Research Paper

\title{
Risk of upgrading from prostate biopsy to radical prostatectomy pathology: Is magnetic resonance imaging-guided biopsy more accurate?
}

\author{
Ning $\mathrm{Xu}^{*}$, Yu-Peng $\mathrm{Wu}^{*}$, Xiao-Dong Li, Min-Yi Lin, Qing-Shui Zheng, Shao-Hao Chen, Jun-Feng Li, Yong \\ Wei ${ }^{\bowtie}$, Xue-Yi Xue $^{\bowtie}$ \\ Departments of Urology, First Affiliated Hospital of Fujian Medical University, Fuzhou 350005, China \\ *These three authors contributed equally to this work. \\ $\triangle$ Corresponding authors: Xue-Yi Xue and Yong Wei, Department of Urology, First Affiliated Hospital of Fujian Medical University, 20 Chazhong Road, \\ Fuzhou 350005, China. Tel.: +86-059187981687; E-mail address: xuexueyi@fjmu.edu.cn (Xue-Yi Xue), weiyong2017@fjmu.edu.cn (Yong Wei) \\ ( ) Ivyspring International Publisher. This is an open access article distributed under the terms of the Creative Commons Attribution (CC BY-NC) license \\ (https://creativecommons.org/licenses/by-nc/4.0/). See http://ivyspring.com/terms for full terms and conditions.
}

Received: 2018.04.20; Accepted: 2018.07.25; Published: 2018.09.08

\begin{abstract}
Background: This study compared magnetic resonance imaging-guided biopsy (MRI-GB) and transrectal ultrasound guided biopsy (TRUS-GB) with the final histology of the radical prostatectomy (RP) specimen.

Methods: Our subjects were 229 patients with prostate cancer ( $\mathrm{PCa})$, proven histopathologically using MRI-GB or TRUS-GB, who underwent RP at our center between December 2015 and December 2016. The main group included 92 patients who underwent MRI-GB and the control group included 137 patients who underwent 12-core TRUS-GB. Histological findings for RP specimens were compared with those from biopsies. We also evaluated predictors of upgraded Gleason score (GS), using uni- and multivariate analyses.

Results: Upgraded GS between biopsy and RP specimen occurred to $22.7 \%$ (52/229) of the cohort overall. In univariate analysis, prostate-specific antigen density (PSAD) $(P<0.001)$, prostate volume $(P V)<30 \mathrm{ml}(P<0.001)$, biopsy modality $(P=0.027)$, biopsy $G S(P=0.032)$ and measured MRI lymph node metastasis $(P=0.018)$ were prognostic factors. Multivariate logistic regression analysis showed $P V<30 \mathrm{ml}(P<0.001)$ and biopsy modality $(P=0.001)$ were independent predictors of upgraded $G S$.

Conclusions: MRI-GB may enhance the diagnostic accuracy of prostate cancer detection in final histopathology with lower rate of upgraded GS than TRUS-GB. Also, PV $<30 \mathrm{ml}$ and biopsy modality were independent predictors of upgraded GS.
\end{abstract}

Key words: MRI; prostate biopsy; prostatectomy specimen; systematic biopsy; Gleason score upgrading.

\section{Introduction}

Clinicians depend heavily on the prostate biopsy Gleason score (GS) to predict tumor aggressiveness and counsel patients for further treatment [1]. Accurate assessment of tumor aggressiveness is essential in diagnosing PCa. Although active surveillance (AS) is often recommended to patients with low-risk PCa to avoid overtreatment [2], GS between prostate biopsy and radical prostatectomy (RP) specimens is occasionally discordant, with GS assessed by surgical specimen often lower than that of biopsy specimen [3]. As a result, PCa risk may be underestimated and patients might not obtain adequate medical care [4]. Reportedly, GS is underestimated in up to $43 \%$ of patients, compared with their radical prostatectomy (RP) specimens [5-7].

Inaccuracy of biopsy-based GS is associated with interobserver variability by different pathologists [8-10], and more significantly, with random error 
from 12 core transrectal ultrasound guided biopsy (TRUS-GB) [10]. Current practice trends suggest that the use of magnetic resonance imaging-guided biopsy (MRI-GB) has been rapidly increasing worldwide and has become a more important diagnostic tool for PCa. MRI-GB is a promising method for accurate assessment of GS, enabling better tumor visualization and targeting of PCa. In-bore MRI prostate biopsy can be used for targeted biopsies. Numerous studies suggest that targeted biopsies reveal significantly greater percentages of cancer involvement in biopsy cores $[5,11-15]$.

The relationship between MRI-GB and final RP specimen histopathology has not been widely studied $[13,16]$. This study compared outcomes from MRI-GB with histological results from RP specimens, and evaluated independent predictive factors for upgraded GS.

\section{Patients and methods}

\section{Patients}

We initially included 245 patients who underwent laparoscopic RP at First Affiliated Hospital of Fujian Medical University in the period from December 2015 to December 2016, after being diagnosed with PCa by MRI-GB or TRUS-GB without distant metastasis at our center, in this retrospective study. We excluded the 16 patients who received neoadjuvant androgen deprivation, chemotherapy radiotherapy, previous prostate surgery, or treatment with 5-alpha reductase inhibitors that could interfere with the histological interpretation of the RP specimen. Finally, 229 cases were included in this study. We prospectively collected data on age, digital rectal exam (DRE), prostate-specific antigen (PSA), prostate volume (PV), prostate-specific antigen density (PSAD), potential lesions and preoperative lymph node metastasis detected by mpMRI, Prostate Imaging Reporting and Data System (PI-RADS) score, biopsy GS, final pathological GS after RP, biopsy cores, positive biopsy cores, tumor-involved positive biopsy cores, clinical stage, and invasion of seminal vesicles.

\section{Multiparametric magnetic resonance imaging}

MpMRI of the prostate was performed on a 3-T MRI scanner (Siemens, Munich, Germany). All patients underwent mpMRI before surgery. The MRI protocol was designed according to recommendations of the European Consensus Meeting (ESUR) on standardization of prostate MRI [17]. To characterize lesions, we calculated the PI-RADS score from the sum of the scores of each sequence (T1-weighted [T1WI], T2-weighted [T2WI], diffusion-weighted
[DWI], dynamic contrast-enhanced MRI [DCE] and magnetic resonance spectroscopy [MRS]) [18]. A PI-RADS $\geq 2$ lesion on MRI was defined as biopsy target. The complete mpMRI data set was analyzed by 2 radiologists, each with at least 4 years of experience with prostate MRIs.

\section{Multiparametric magnetic resonance imaging targeted biopsy}

A total of 92 patients underwent mpMRI, all under local anesthesia, to locate their potential prostate lesions. After that, patients were placed in the decubitus position in a 3.0-T MRI scanner (Siemens, Munich, Germany), and underwent transperineal biopsy with an MRI-compatible, 18-gauge, semi-automatic biopsy gun (model: TZ 18/16 18 G×16 $\mathrm{cm}$, i-MED, Suzhou, China), in which two targeted biopsy cores were taken from potential prostate lesion. Urethra, bladder and rectal injury and hemorrhage were reevaluated after biopsy. All mpMRI-GBs were performed by the same expert urologist.

\section{Transrectal ultrasound guided biopsy}

A total of 137 patients underwent TRUS-GB using color Doppler ultrasonography (SiemensAcuson, Aspen, USA). With a 18-gauge, fully automatic biopsy gun (Max-Core, Bard, America), all 137 patients underwent 12-core TRUS-GB, including 6 sextant biopsy cores with 6 additional biopsy cores taken at the base, mid gland and apex of the prostate on the right and left sides[19]. Patients received 500 $\mathrm{mg}$ oral ciprofloxacin on the night before, as standard antibiotic prophylaxis. All TRUS-GBs were performed by the same urologist [20].

\section{Radical prostatectomy}

All patients underwent RP, which were performed by the same experienced urologist.

\section{Pathological analysis}

Specimens from needle biopsies and RP were assessed by the same expert pathologist from Department of Pathology in our center. We followed the recommendations of the 2005 International Society of Urological Pathology consensus for GS [21]. The highest-grade pattern was recorded. Upgraded GS was defined as any increased total sum in the pathological GS compared with that of the biopsy GS [11]. In addition, increased main structure score without changing the total sum was also defined as an upgraded GS.

\section{Statistical analysis}

Normally distributed parameters were compared between the TRUS-GB and MRI-GB 
groups, using Student's $t$-test for independent groups. Nonparametric data were tested using the Mann-Whitney U test. Normally distributed data are shown as the mean \pm standard deviation (SD), and other data are shown as the median and interquartile range (IQR). Clinical and pathologic parameters were analyzed by univariate (chi-square test) and multivariate (logistic regression model) methods. The statistical program SPSS, version 19, (SPSS, Chicago, I) was used. $P<0.05$ was considered significant [22].

\section{Results}

The MRI-GB group $(\mathrm{n}=92)$ and the TRUS-GB group $(n=137)$ did not significantly differ in baseline characteristics, including age, DRE results, PSA level, PSAD, mean tumor involvement positive biopsy cores, or PI-RADS score $(P>0.05$, Table 1$)$, but did differ with respect to $P V$, biopsy cores and proportion of cancer involvement $(P<0.05$, Table 1$)$. Percentage distribution of the highest GS is shown in Table 2. MRI-GB detected 10 (10.9\%) GS 6, 43 (46.7\%) GS 7 $(3+4), 11(12.0 \%)$ GS $7(4+3)$, and $28(30.4 \%)$ GS $\geq 8$ tumors. TRUS-GB detected 23 (16.8\%) GS 6, $32(23.4 \%)$ GS $7(3+4), 39(28.5 \%)$ GS $7(4+3)$ and $43(31.4 \%)$ GS $\geq 8$ tumors.

Table 1. Baseline characteristics of included patients

\begin{tabular}{|c|c|c|c|}
\hline Variable & TRUS-GB & MpMRI-TB & $P$ value \\
\hline Case, $\mathrm{n}$ & 137 & 92 & \\
\hline Age, year (rang) & $66(53.0-77.0)$ & $67.5(53.0-78.0)$ & 0.754 \\
\hline DRE, n (\%) & & & 0.205 \\
\hline Normal & $81(59.1 \%)$ & $62(67.4 \%)$ & \\
\hline Abnormal & $56(40.9 \%)$ & $30(32.6 \%)$ & \\
\hline PSA, ng/ml (rang) & $15.5(0.4-156.0)$ & $14.6(4.0-114.0)$ & 0.199 \\
\hline Prostate volume, ml (rang) & $31.5(10.6-91.1)$ & $39.9(13.5-85.0)$ & $<0.001^{*}$ \\
\hline $\mathrm{PSAD}, \mathrm{ng} / \mathrm{ml} / \mathrm{ml}$ (rang) & $0.5(0.0-14.8)$ & $0.4(0.1-2.7)$ & 0.278 \\
\hline Average PI-RADS score (rang) & $3(3.0-5.0)$ & $4(3.0-5.0)$ & 0.717 \\
\hline Biopsy cores/case, $\mathrm{n}$ (rang) & $12(1.0-12.0)$ & $2(0.6-12.0)$ & $<0.001^{*}$ \\
\hline Positive biopsy cores, (rang) & $6(1.0-15.0)$ & $6(1.0-19.0)$ & 0.064 \\
\hline $\begin{array}{l}\text { Proportion of cancer involvement, \% } \\
\text { (rang) }\end{array}$ & $26.8(4.6-100.0)$ & $31.8(7.5-100.0)$ & $<0.001^{*}$ \\
\hline
\end{tabular}

Table 2. Overview of highest Gleason scores from the mPMRI-TB and TRUS-GB groups.

\begin{tabular}{lllllll}
\hline Highest Gleason score & TRUS-GB & \multicolumn{3}{l}{ MpMRI-TB } & Total \\
\hline $3+3=6$ & 23 & $10.0 \%$ & 10 & $4.4 \%$ & 33 & $14.4 \%$ \\
$3+4=7$ & 32 & $14.0 \%$ & 43 & $18.8 \%$ & 75 & $32.8 \%$ \\
$4+3=7$ & 39 & $17.0 \%$ & 11 & $4.8 \%$ & 50 & $21.8 \%$ \\
$\geq 8$ & 43 & $18.8 \%$ & 28 & $12.2 \%$ & 71 & $31.0 \%$ \\
Total & 137 & $59.8 \%$ & 92 & $40.2 \%$ & 229 & $100.0 \%$
\end{tabular}

MpMRI-TB: multiparametric magnetic resonance imaging targeted biopsy, TRUS-GB: transrectal ultrasound guided biopsy.

Concordance of GS between biopsy specimens and final pathological specimens after RP is shown in Table 3. All cases were divided into an upgraded subgroup $(n=52)$ and a non-upgraded subgroup $(n=177)$. Independent risk factors associated with upgraded GS were subsequently analyzed. Univariate analysis demonstrated that age, PSA, PI-RADS score, clinical stage, final pathological GS, invasion of seminal vesicles, invasion of capsule and positive cores did not significantly differ between the two subgroups $(P>0.05$, Table 4$)$; but they did differ in PSAD $(P<0.001)$, PV $(P<0.001)$, biopsy modality $(P=0.027)$, biopsy GS $(P=0.032)$ and lymph node metastasis $(P=0.018)$. In multivariate logistic regression analysis, only PV $(P<0.001)$ and biopsy modality $(P=0.001)$ were independent predictors of GSU after RP (Table 5).

Table 3. Concordance of Gleason score between biopsies and radical prostatectomy specimen in the mPMRI-TB and TRUS-GB groups

\begin{tabular}{|c|c|c|c|c|c|}
\hline & \multicolumn{5}{|c|}{ Radical prostatectomy } \\
\hline & GS $3+3=6$ & GS $3+4=7$ & GS $4+3=7$ & $\mathrm{GS} \geq 8$ & Total \\
\hline \multicolumn{6}{|l|}{ mpMRI-TB } \\
\hline GS $3+3=6$ & 8 & 1 & 1 & 0 & 10 \\
\hline GS $3+4=7$ & 0 & 33 & 10 & 0 & 43 \\
\hline GS $4+3=7$ & 0 & 0 & 9 & 2 & 11 \\
\hline $\mathrm{GS} \geq 8$ & 0 & 0 & 0 & 28 & 28 \\
\hline Total & 8 & 34 & 20 & 30 & 92 \\
\hline \multicolumn{6}{|l|}{ TRUS-GB } \\
\hline GS $3+3=6$ & 6 & 8 & 9 & 0 & 23 \\
\hline GS $3+4=7$ & 0 & 28 & 0 & 4 & 32 \\
\hline GS $4+3=7$ & 0 & 4 & 26 & 9 & 39 \\
\hline $\mathrm{GS} \geq 8$ & 0 & 4 & 10 & 29 & 43 \\
\hline Total & 6 & 44 & 45 & 42 & 137 \\
\hline
\end{tabular}

MpMRI-TB: multiparametric magnetic resonance imaging targeted biopsy, TRUS-GB: transrectal ultrasound guided biopsy.

Table 4. Univariate analysis of possible GS predictors

\begin{tabular}{|c|c|c|c|}
\hline Variables & Non-upgrading & Upgrading & P value \\
\hline Case, $\mathrm{n}(\%)$ & 177 & 52 & \\
\hline Age, year(rang) & $66.0(53.0-77.0)$ & $68.0(57.0-78.0)$ & 0.122 \\
\hline PSA, ng/ml(rang) & $15.0(0.7-114.0)$ & $14.8(0.4-156.0)$ & 0.577 \\
\hline $\mathrm{PSAD}, \mathrm{ng} / \mathrm{ml} / \mathrm{ml}$ (rang) & $0.4(0.0-2.7)$ & $0.5(0.0-14.8)$ & $<0.001$ * \\
\hline Prostate volume & & & $<0.001^{*}$ \\
\hline$<30 \mathrm{ml}$ & $24(13.6 \%)$ & $40(76.9 \%)$ & \\
\hline$\geq 30 \mathrm{ml}$ & $153(86.4 \%)$ & $12(23.1 \%)$ & \\
\hline Biopsy modality, n (\%) & & & $0.027^{*}$ \\
\hline mpMRI-TB & $78(44.1 \%)$ & $14(26.9 \%)$ & \\
\hline TRUS-GB & $99(55.9 \%)$ & $38(73.1 \%)$ & \\
\hline PI-RADS score, $\mathrm{n}(\%)$ & & & 0.535 \\
\hline 3 & $90(50.8 \%)$ & $28(53.8 \%)$ & \\
\hline 4 & $40(22.6 \%)$ & $14(26.9 \%)$ & \\
\hline 5 & $47(26.6 \%)$ & $10(19.2 \%)$ & \\
\hline Clinical stage, $\mathrm{n}(\%)$ & & & 0.148 \\
\hline T1c & $29(16.4 \%)$ & $6(11.5 \%)$ & \\
\hline $\mathrm{T} 2 \mathrm{a}$ & $31(17.5 \%)$ & $17(32.7 \%)$ & \\
\hline $\mathrm{T} 2 \mathrm{~b}$ & $24(13.6 \%)$ & $4(7.7 \%)$ & \\
\hline $\mathrm{T} 2 \mathrm{c}$ & $52(29.4 \%)$ & $11(21.2 \%)$ & \\
\hline T3a & $39(22.0 \%)$ & $14(26.9 \%)$ & \\
\hline $\mathrm{T} 3 \mathrm{~b}$ & $2(1.1 \%)$ & $0(0.0 \%)$ & \\
\hline Biopsy Gleason score, n (\%) & & & $0.032^{*}$ \\
\hline$<7$ & $17(9.6 \%)$ & $11(21.2 \%)$ & \\
\hline$\geq 7$ & $160(90.4 \%)$ & $41(78.8 \%)$ & \\
\hline Postoperative Gleason score, n (\%) & & & 0.201 \\
\hline$<7$ & $14(7.9 \%)$ & $1(1.9 \%)$ & \\
\hline$\geq 7$ & $163(92.1 \%)$ & $51(98.1 \%)$ & \\
\hline Invasion of seminal vesicle, $\mathrm{n}(\%)$ & & & 0.421 \\
\hline No & $113(63.8 \%)$ & $30(57.7 \%)$ & \\
\hline Yes & $64(36.2 \%)$ & $22(42.3 \%)$ & \\
\hline
\end{tabular}




\begin{tabular}{llll}
\hline Variables & Non-upgrading & Upgrading & P value \\
\hline Invasion of capsule, $\mathrm{n}(\%)$ & & & 0.198 \\
No & $86(48.6 \%)$ & $20(38.5 \%)$ & \\
Yes & $91(51.4 \%)$ & $32(61.5 \%)$ & \\
Lymph node metastasis, n (\%) & & & $0.018^{*}$ \\
No & $135(76.3 \%)$ & $31(59.6 \%)$ & \\
Yes & $42(23.7 \%)$ & $21(40.4 \%)$ & \\
Positive biopsy cores , n (rang) & $6.0(1.0-19.0)$ & $6.0(1.0-16.0)$ & 0.907 \\
\hline
\end{tabular}

${ }^{*} P<0.05$; PSA: Prostate specific antigen, PSAD: prostate-specific antigen density, PI-RADS: Prostate Imaging Reporting and Data System.

Table 5. Multivariate logistic regression of independent predictors of upgraded GS after radical prostatectomy

\begin{tabular}{lll}
\hline Variable & P value & Odd ratio (95\% confidence interval) \\
\hline PSAD & 0.273 & $0.8(0.6,1.1)$ \\
PV $(<30 \mathrm{ml}$ vs. $\geq 30 \mathrm{ml})$ & $<0.001^{*}$ & $0.7(0.6,0.8)$ \\
Biopsy modality & $0.001^{*}$ & $12.1(2.6,55.4)$ \\
Biopsy Gleason score $(<7$ & 0.367 & $0.4(0.1,3.0)$ \\
vs. $\geq 7)$ & & \\
Lymph node metastasis & 0.734 & $0.8(0.3,2.3)$ \\
${ }^{*} P<0.05 ;$ PSAD: prostate-specific antigen density, PV: prostate volume.
\end{tabular}

\section{Discussion}

Gleason scores are important for therapeutic decisions with regard to prostate cancers [23, 24]. They can predict time to development of metastatic disease for patients who undergo radiation therapy (RT) [25], and inform therapeutic strategy. Accuracy of GS is therefore very important, especially for those patients who require treatments other than RP, such as AS or RT. Underestimated GS may lead to insufficient therapy; patients may lose the opportunity for optimal treatment. Hence, correct GS from biopsy is important.

Although TRUS-GB remains the golden standard in PCa diagnosis, its large sampling error suggests low reliability. The GS is often underestimated by TRUS-GB, which contributes to upgraded GS after RP. King et al. [7] declared the upgraded GS rate after RP to be $35-43 \%$; Cohen et al. [6] found the upgraded GS to be $30 \%$; a study from Lahey clinical center $(n=2890)$ showed the upgraded GS rate to be $36 \%$ (consistent with Cohen's study[6]); Milonas et al. [26] reported an upgraded GS rate of $38.2 \%(n=241)$; and Suer et al. [27] in a study of 632 patients who underwent RP, found an upgraded GS rate of $28.9 \%$, with a GS concordance rate of $59.8 \%$. Our study showed an upgraded GS rate of $22.7 \%$, which was concordant with previous studies.

In multivariate logistic regression analysis, we found biopsy modality and smaller prostate volumes $(<30 \mathrm{ml})$ were independent predictors of upgraded GS after RP. We also found MRI-GB to provide higher concordance on histological GS between biopsy and RP specimens than did TRUS-GB. Previous studies reported GS concordance rates between in-bore MRI-GB and RP specimens as 57-90\% [5, 12], which aligned with our results. The study of Le et al. [28] suggested that the GS concordance rate was $81 \%$, and the upgraded GS rate was $17 \%$, among 54 patients who underwent targeted biopsy using MRI ultrasound fusion. However, Arsov et al.[19] found the upgraded GS rates for MRI-GB and TRUS-GB were $40.4 \%$ and $50.0 \%$, respectively.

We found that PV $<30 \mathrm{ml}$ was an independent risk factor for upgraded GS after RP. Of the 64 patients whose PV was less than $30 \mathrm{ml}, 62.5 \%(40 / 64)$ had upgraded GS, compared with 7.3\% (12/165) of the patients with larger PV. Freedland et al. [29] reported that the smaller prostates are correlated with higher pathological grade and have biologically more aggressive behavior. Because of a greater likelihood that high grade disease exists, smaller prostates are more likely upgraded. Another explanation is that the PSA level is commonly influenced by gland volume and not by cancer. However, PSA level drives biopsy recommendations. As described by previous studies [30-32], the concomitant presence of a large volume, benign gland is a confounding factor in the relationship between prostate cancer and PSA. Turley et al. [33] found that men with PV $\leq 20 \mathrm{~cm}^{3}$ were 5 times more likely to be upgraded than were men with PV $>60 \mathrm{~cm}^{3}$. Moon et al. [34] found that PV $\leq 36.6 \mathrm{~cm}^{3}$ was an independent risk factor for upgraded GS among patients from Asia. Chung et al. [35] reported that smaller PV was a predictor of upgraded GS after $R P$; men with $P V \leq 25 \mathrm{~cm}^{3}$ were 2.7 times more likely to be upgraded than men with PV $>40 \mathrm{~cm}^{3}$.

There are limitations in this study. Firstly, this retrospective study was a single center design with a small sample size. Secondly, trails are needed to test MRI as a screening or upfront test compared to standard 12-core TRUS. Thirdly, some researchers reveals that mpMRI holds the promise of eliminating unnecessary biopsies, mpMRI can then be used as a triage test in the population with negative test result[36-38]. However, this topic was not discussed in our study.

In a word, we found that MRI-GB decreased the rate of upgraded GS after RP, and biopsy modality and smaller PV were independent predictors of upgraded GS. Further studies are needed to explore the relationship between MRI-GB and GS to aid urologists in assessing patients and making therapeutic decisions.

\section{Clinical Practice Points}

Numerous studies indicate that targeted biopsies reveal significantly greater percentages of cancer involvement in biopsy cores. However, the relationship between MRI-GB and final RP specimen histopathology has not been widely studied. We found that MRI-GB may enhance the diagnostic 
accuracy of prostate cancer detection in final histopathology with lower rate of upgraded GS than TRUS-GB, which may contribute to better therapeutic decisions. Biopsy modality and smaller PV were independent predictors of upgraded GS.

\section{Acknowledgements}

\section{Funding}

This study was supported by the Joint Foundation of Fujian Province for Science and Technology Innovative Research Project (Grant number: 2017Y9093), Natural Science Foundation of Fujian Province (Grant number: 2017J01197), the Youth Foundation of Health and Family Planning Commission of Fujian Province, China (Grant number: 2017-1-58), Natural Science Foundation of Fujian Province (Grant number: 2018J01177), and Startup Fund for scientific research, Fujian Medical University (Grant number: 2017XQ2041), the Creative Program of Health and Family Planning Commission of Fujian Province, China (Grant number: 2015-CX-24).

\section{Availability of data and materials}

All data generated or analyzed during this study are included in this published article.

\section{Ethics approval and consent to participate}

The project was approved by the Institutional Ethics Committee of First Affiliated Hospital of Fujian Medical University. Informed consent was obtained from all the patients or their relatives prior to analysis.

\section{Authors' contributions}

Conception/Design: Ning $\mathrm{Xu}, \mathrm{Yu}-\mathrm{Peng} \mathrm{Wu}$, Xiao-Dong Li; Provision of study material or patients: Min-Yi Lin, Qing-Shui Zheng; Collection and/or assembly of data: Shao-Hao Chen, Jun-Feng Li; Data analysis and interpretation: Yong Wei, Xue-Yi Xue; Manuscript writing: Ning $\mathrm{Xu}$, Yu-Peng $\mathrm{Wu}$, Xiao-Dong Li; Final approval of manuscript: Qing-Shui Zheng, Yong Wei, Xue-Yi Xue.

\section{Competing Interests}

The authors have declared that no competing interest exists.

\section{References}

1. Epstein JI, Egevad L, Amin MB, Delahunt B, Srigley JR, Humphrey PA. The 2014 International Society of Urological Pathology (ISUP) Consensus Conference on Gleason Grading of Prostatic Carcinoma: Definition of Grading Patterns and Proposal for a New Grading System. Am J Surg Pathol. 2016; 40(2): 244-52.

2. Wilt TJ, Brawer MK, Jones KM, Barry MJ, Aronson WJ, Fox S, et al. Radical prostatectomy versus observation for localized prostate cancer. N Engl J Med. 2012; 367(3): 203-13.

3. Hoeks CM, Somford DM, van Oort IM, Vergunst H, Oddens JR, Smits GA, et al. Value of 3-T multiparametric magnetic resonance imaging and magnetic resonance-guided biopsy for early risk restratification in active surveillance of low-risk prostate cancer: a prospective multicenter cohort study. Invest Radiol. 2014; 49(3): 165-72.

4. Epstein JI, Feng Z, Trock BJ, Pierorazio PM. Upgrading and downgrading of prostate cancer from biopsy to radical prostatectomy: incidence and predictive factors using the modified Gleason grading system and factoring in tertiary grades. Eur Urol. 2012; 61(5): 1019-24.

5. Borkowetz A, Platzek I, Toma M, Renner T, Herout R, Baunacke M, et al Direct comparison of multiparametric magnetic resonance imaging (MRI) results with final histopathology in patients with proven prostate cancer in MRI/ultrasonography-fusion biopsy. BJU Int. 2016; 118(2): 213-20.

6. Cohen MS, Hanley RS, Kurteva T, Ruthazer R, Silverman ML, Sorcini A, et al. Comparing the Gleason prostate biopsy and Gleason prostatectomy grading system: the Lahey Clinic Medical Center experience and an international meta-analysis. Eur Urol. 2008; 54(2): 371-81.

7. King CR, Long JP. Prostate biopsy grading errors: a sampling problem? Int J Cancer. 2000; 90(6): 326-30.

8. Berg KD, Toft BG, Roder MA, Brasso K, Vainer B, Iversen P. Prostate needle biopsies: interobserver variation and clinical consequences of histopathological re-evaluation. Apmis. 2011; 119(4-5): 239-46.

9. McKenney JK, Simko J, Bonham M, True LD, Troyer D, Hawley S, et al. The potential impact of reproducibility of Gleason grading in men with early stage prostate cancer managed by active surveillance: a multi-institutional study. J Urol. 2011; 186(2): 465-9.

10. $\mathrm{Hu}$ Y, Ahmed HU, Carter T, Arumainayagam N, Lecornet E, Barzell W, et al. A biopsy simulation study to assess the accuracy of several transrectal ultrasonography (TRUS)-biopsy strategies compared with template prostate mapping biopsies in patients who have undergone radical prostatectomy. BJU Int. 2012; 110(6): 812-20.

11. Quentin M, Blondin D, Arsov C, Schimmoller L, Hiester A, Godehardt E, et al. Prospective evaluation of magnetic resonance imaging guided in-bore prostate biopsy versus systematic transrectal ultrasound guided prostate biopsy in biopsy naive men with elevated prostate specific antigen. J Urol. 2014; 192(5): 1374-9.

12. Haffner J, Lemaitre L, Puech P, Haber GP, Leroy X, Jones JS, et al. Role of magnetic resonance imaging before initial biopsy: comparison of magnetic resonance imaging-targeted and systematic biopsy for significant prostate cancer detection. BJU Int. 2011; 108(8 Pt 2): E171-8.

13. Delongchamps NB, Lefevre A, Bouazza N, Beuvon F, Legman P, Cornud F. Detection of significant prostate cancer with magnetic resonance targeted biopsies--should transrectal ultrasound-magnetic resonance imaging fusion guided biopsies alone be a standard of care? J Urol. 2015; 193(4): 1198-204.

14. Radtke JP, Schwab C, Wolf MB, Freitag MT, Alt CD, Kesch C, et al. Multiparametric Magnetic Resonance Imaging (MRI) and MRI-Transrectal Ultrasound Fusion Biopsy for Index Tumor Detection: Correlation with Radical Prostatectomy Specimen. Eur Urol. 2016; 70(5): 846-853.

15. Baco E, Rud E, Eri LM, Moen G, Vlatkovic L, Svindland A, et al. A Randomized Controlled Trial To Assess and Compare the Outcomes of Two-core Prostate Biopsy Guided by Fused Magnetic Resonance and Transrectal Ultrasound Images and Traditional 12-core Systematic Biopsy. Eur Urol. 2016; 69(1): 149-56.

16. Baco E, Rud E, Vlatkovic L, Svindland A, Eggesbo HB, Hung AJ, et al. Predictive value of magnetic resonance imaging determined tumor contact length for extracapsular extension of prostate cancer. J Urol. 2015; 193(2): 466-72.

17. Riccabona M, Lobo ML, Willi U, Avni F, Damasio B, Ording-Mueller LS, et al. ESPR uroradiology task force and ESUR Paediatric Work Group--Imaging recommendations in paediatric uroradiology, part VI: childhood renal biopsy and imaging of neonatal and infant genital tract. Minutes from the task force session at the annual ESPR Meeting 2012 in Athens on childhood renal biopsy and imaging neonatal genitalia. Pediatr Radiol. 2014; 44(4): 496-502.

18. Barentsz JO, Richenberg J, Clements R, Choyke P, Verma S, Villeirs G, et al. ESUR prostate MR guidelines 2012. Eur Radiol. 2012; 22(4): 746-57.

19. Arsov C, Becker N, Rabenalt R, Hiester A, Quentin M, Dietzel F, et al. The use of targeted MR-guided prostate biopsy reduces the risk of Gleason upgrading on radical prostatectomy. J Cancer Res Clin Oncol. 2015; 141(11): 2061-8.

20. Gore JL, Shariat SF, Miles BJ, Kadmon D, Jiang N, Wheeler TM, et al. Optimal combinations of systematic sextant and laterally directed biopsies for the detection of prostate cancer. J Urol. 2001; 165(5): 1554-9.

21. Danneman D, Drevin L, Delahunt B, Samaratunga $H$, Robinson D, Bratt O, et al. Accuracy of prostate biopsies for predicting Gleason score in radical prostatectomy specimens: nationwide trends 2000-2012. BJU Int. 2017; 119(1): 50-56

22. Wu YP, Lin TT, Chen SH, Xu N, Wei Y, Huang JB, et al. Comparison of the efficacy and feasibility of en bloc transurethral resection of bladder tumor versus conventional transurethral resection of bladder tumor: A meta-analysis. Medicine (Baltimore). 2016; 95(45): e5372.

23. Dall'Era MA, Albertsen PC, Bangma C, Carroll PR, Carter HB, Cooperberg $\mathrm{MR}$, et al. Active surveillance for prostate cancer: a systematic review of the literature. Eur Urol. 2012; 62(6): 976-83.

24. Heidenreich A, Bastian PJ, Bellmunt J, Bolla M, Joniau S, van der Kwast T, et al. EAU guidelines on prostate cancer. part 1: screening, diagnosis, and local treatment with curative intent-update 2013. Eur Urol. 2014; 65(1): 124-37.

25. Zhou P, Chen MH, McLeod D, Carroll PR, Moul JW, D'Amico AV. Predictors of prostate cancer-specific mortality after radical prostatectomy or radiation therapy. J Clin Oncol. 2005; 23(28): 6992-8. 
26. Milonas D, Grybas A, Auskalnis S, Gudinaviciene I, Baltrimavicius R, Kincius $\mathrm{M}$, et al. Factors predicting Gleason score 6 upgrading after radical prostatectomy. Cent European J Urol. 2011; 64(4): 205-8.

27. Suer E, Gokce MI, Gulpinar O, Guclu AG, Haciyev P, Gogus C, et al. How significant is upgrade in Gleason score between prostate biopsy and radical prostatectomy pathology while discussing less invasive treatment options? Scand J Urol. 2014; 48(2): 177-82.

28. Le JD, Stephenson S, Brugger M, Lu DY, Lieu P, Sonn GA, et al. Magnetic resonance imaging-ultrasound fusion biopsy for prediction of final prostate pathology. J Urol. 2014; 192(5): 1367-73.

29. Freedland SJ, Isaacs WBPlatz EA, Terris MK, Aronson WJ, Amling CL, Jr PJ, et al. Prostate size and risk of high-grade, advanced prostate cancer and biochemical progression after radical prostatectomy: a search database study. J Clin Oncol. 2005; 23(30): 7546.

30. Kassouf W, Nakanishi H, Ochiai A, Babaian KN, Troncoso P, Babaian RJ. Effect of prostate volume on tumor grade in patients undergoing radical prostatectomy in the era of extended prostatic biopsies. J Urol. 2007; 178(1): 111-114.

31. Chen ME, Troncoso P, Johnston D, Tang K, Babaian RJ. Prostate cancer detection: relationship to prostate size. Urology. 1999; 53(4): 764-768.

32. Kojima M, Troncoso P, Babaian RJ. Influence of noncancerous prostatic tissue volume on prostate-specific antigen. Urology. 1998; 51(2): 293-299.

33. Turley RS, Hamilton RJ, Terris MK, Kane CJ, Aronson WJ, Presti JC, Jr., et al. Small transrectal ultrasound volume predicts clinically significant Gleason score upgrading after radical prostatectomy: results from the SEARCH database. J Urol. 2008; 179(2): 523-7; discussion 527-8.

34. Moon SJ, Park SY, Lee TY. Predictive factors of Gleason score upgrading in localized and locally advanced prostate cancer diagnosed by prostate biopsy. Korean J Urol. 2010; 51(10): 677-82.

35. Chung MS, Lee SH, Lee DH, Chung BH. Is small prostate volume a predictor of Gleason score upgrading after radical prostatectomy? Yonsei Med J. 2013; 54(4): 902-6.

36. Abd-Alazeez M, Ahmed HU, Arya M, Charman SC, Anastasiadis E, Freeman A, et al. The accuracy of multiparametric MRI in men with negative biopsy and elevated PSA level--can it rule out clinically significant prostate cancer? Urol Oncol. 2014; 32(1): 45.e17-22.

37. Ahmed HU, El-Shater Bosaily A, Brown LC, Gabe R, Kaplan R, Parmar MK, et al. Diagnostic accuracy of multi-parametric MRI and TRUS biopsy in prostate cancer (PROMIS): a paired validating confirmatory study. Lancet. 2017; 389(10071): 815-822.

38. Kasivisvanathan V, Jichi F, Klotz L, Villers A, Taneja SS, Punwani S, et al. A multicentre randomised controlled trial assessing whether MRI-targeted biopsy is non-inferior to standard transrectal ultrasound guided biopsy for the diagnosis of clinically significant prostate cancer in men without prior biopsy: a study protocol. BMJ Open. 2017; 7(10): e017863. 